\title{
The Fundamentals in US Presidential Elections: Public Opinion, the Economy and Incumbency in the 2004 Presidential Election
}

\author{
JAMES E. CAMPBELL \\ Department of Political Science, University at Buffalo, SUNY, Buffalo, NY, USA
}

\begin{abstract}
Presidential elections are largely structured by certain fundamentals that are in place before the campaigns begin. These are the public's opinion about the in-party and the candidate choice, the general state of the election-year economy, and incumbency. This trinity of fundamentals have in various ways been incorporated into statistical models that accurately forecast the major party division of the popular vote well before Election Day. This article examines the historical associations between several indicators of these fundamental forces and the national vote. It also examines the state of these indicators in the 2004 presidential election. They indicate that the fundamentals leading into the 2004 campaign generally favoured George W. Bush and anticipated his re-election.
\end{abstract}

The modern science of presidential election forecasting is entering its third decade. ${ }^{1}$ What began with the recognition of the relationship between the public's approval of presidential job performance and the election returns has grown into a field with a diverse array of evolving statistical models of the presidential vote. The models differ in their predictor variables and often in the elections used to estimate the forecast equation. However, beneath all of the diversity at the surface, three pre-campaign fundamentals, tapped in different ways, provide the basis for most of the models. This trinity is the state of public opinion about the in-party candidate and his opponent at the outset of the campaign, the economic conditions of the nation before the campaign and the status of presidential incumbency. ${ }^{2}$ The purpose of this article is two-fold: first, to demonstrate that the three pre-campaign fundamentals of public opinion, the economy and incumbency are associated with the post-campaign division of the popular national vote and second, to discuss the

Correspondence Address: James E. Campbell, Department of Political Science, 520 Park Hall, North Campus, University at Buffalo, SUNY, Buffalo, NY 14260, USA. Email: jcampbel@buffalo.edu 
constellation of these fundamentals that established much of the context for the 2004 presidential election campaign.

Before examining the general relation of these predictors to the vote and their status in 2004, in order to dispel any mystery about why the models work, reasons should be provided as to why one would expect these fundamentals to predict the vote. Sceptical political observers might argue that campaign messages, party platforms and candidate campaigning are what influence voters. Elections are about which candidate and party are entrusted by voters with leading the nation for the next four years. Campaigns are certainly about communication - largely from the candidates to the voters - and what the candidates say and how they say it is important. However, the campaign as communication depends every bit as much on what the voters think at the outset of the campaign, their receptivity to each candidate's message, and the factors that might affect this receptivity over the course of the campaign as it does on what the candidates are trying to communicate to the electorate. This is where the fundamentals come in. The fundamentals reveal where the voters stand as the campaign gets under way and whether they are inclined toward the in-party candidate's message or to the opposition's. ${ }^{3}$ Moreover, the messages that candidates put forth in their campaigns are shaped to no small degree by their pre-campaign circumstances. A strong election-year economy, for instance, should provide an in-party candidate with an opportunity to make a strong appeal to voters for continuity in government.

In addition, it is also clear that a majority of voters (a mean of 58\% in elections from 1952 to 2004) indicate that they made up their minds how they would vote before the campaign was under way (Campbell, 2000: Table B.12). The fundamentals are not just a matter of predisposing these voters towards one candidate when observing the campaign, but provide the basis for a large number of voters to reach an early decision about how they will vote. The record of the in-party and the standing decision of many voters in favour of one party are established well in advance of the campaign and allow for early vote decisions. So the fundamentals are important because they reveal both what those who are decided will do and how those who are undecided (whether just slightly or truly "up in the air") are likely to respond to appeals made to them in the campaign.

The following sections review some of the history of the trinity of fundamentals in US presidential elections and where these fundamentals stood on the threshold of the 2004 campaign.

\section{Public Opinion}

Public opinion leading into a campaign season is the most important of the fundamentals. ${ }^{4}$ The virtue of broad-based public opinion indicators is that they reflect the public's general impressions of the in-party and its opposition on a wide range of issues (from war to the economy) and candidate qualities that the public regards as important. Two indicators of public opinion before the fall campaign have been closely related to the vote in November: the public's approval in July of the president's job 


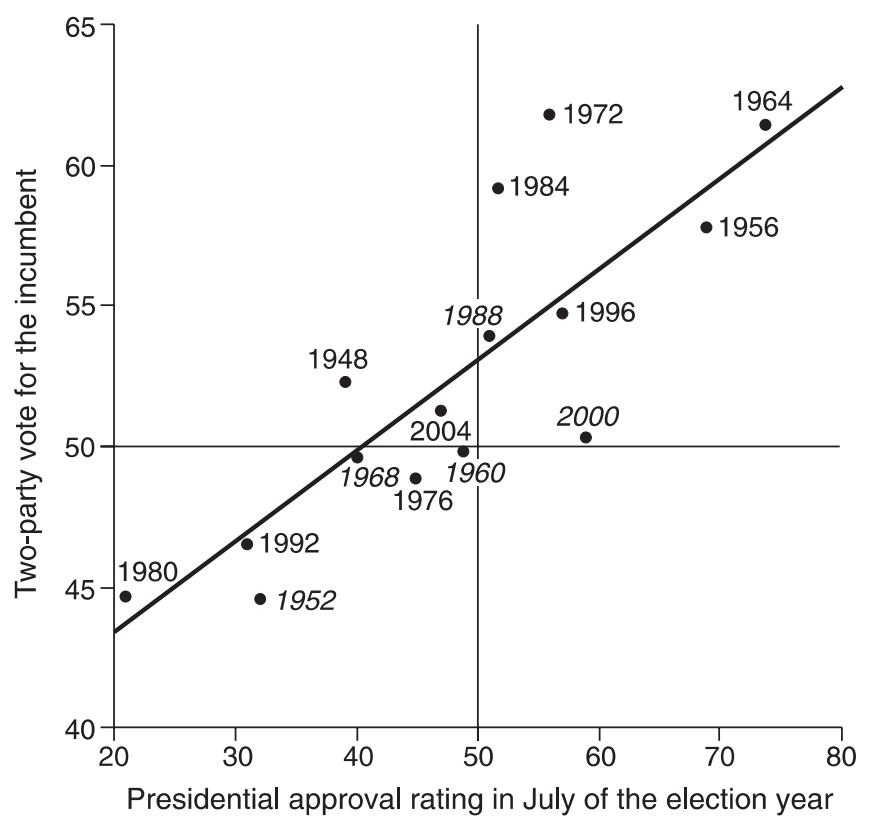

Figure 1. Presidential approval in July and the incumbent's two-party presidential vote, 1948-2004.

Note: The presidential vote is the percentage of the major two-party vote. In-party candidates who are not incumbents are italicized $(1952,1960,1968,1988$ and 2000). The estimated regression is $36.96+(0.32 \mathrm{x}$ July approval rating $)$. The adjusted R-square is 0.65 . The t-ratio for the approval coefficient is 5.18. The standard error of the equation is 3.31. The data are from Gallup (2004) and Moore et al. (2001).

performance and the preference poll in the first week of September (around Labor Day). Both indicators are from surveys conducted by Gallup and are available for the 15 elections from 1948 to 2004. In general, the job approval numbers have been more closely associated with the vote before the parties' national nominating conventions (held in July and August) and the preference polls have been more indicative of the direction of the electorate after the conventions.

Figure 1 plots presidential job approval in July of the election year against the inparty candidates' share of the major party vote for elections from 1948 to 2004. The diagonal line in the plot is the estimated bivariate regression line. The correlation between July approval and vote has been very strong $(\mathrm{r}=.82$ and .87 when the incumbent is running). Every additional three points of approval in July has typically translated into an additional percentage point of the vote in November. Every in-party candidate who has had an approval rating in July of over 50\% has received more than $50 \%$ of the two-party popular vote in November. At the other end of the spectrum, each of the three in-party candidates with July approval ratings for their incumbent of less than $35 \%$ were defeated. The fact that the regression line cuts through the horizontal $50 \%$ of the vote line before the vertical $50 \%$ approval line 
means that in-party candidates can expect to win $50 \%$ of the vote with an approval rating falling short of $50 \%$. The 1968 case illustrates the point. With Lyndon Johnson's approval rating at $40 \%$ in July, his party's standard-bearer Hubert Humphrey received nearly $50 \%$ of the two-party popular vote. The relationship is not determinative of the election - Ford in 1976 and Nixon in 1960 went into the campaign with approval ratings in the upper $40 \%$ range, but fell short of securing a popular vote plurality. Gore entered the 2000 election with Clinton's approval rating in July at $59 \%$, yet fell well short of the vote normally expected from a candidate running under such a favourable condition. Nevertheless, it would appear that inparty candidates with approval ratings in the mid-40s and above are normally in good shape.

In the 2004 election, President George W. Bush's approval rating in July stood at $47 \%$. Although slightly below the $50 \%$ mark, historically this level of approval indicated a slight Bush advantage leading into the 2004 campaign. Based on the regression of approval and the vote, an in-party candidate with $47 \%$ approval in July could expect about $52.1 \%$ of the vote in November. Bush's actual vote in 2004 was only slightly lower: $51.2 \%$.

Figure 2 plots the in-party candidate's share of the early September preference poll against that candidate's share of the vote for elections from 1948 to 2004. The diagonal regression line indicates that a candidate can expect to keep about half of any poll lead to survive or to make up about half of any poll deficit between early September and Election Day. The correlation between the early September preference poll and the vote has been quite strong $(r=.86)$. Each of the seven in-party candidates who began September with at least $51 \%$ of support in the preference poll has received a November vote plurality.

The Gallup poll released on 6 September 2004 indicated that $49 \%$ of registered voters said that they intended to vote for President George W. Bush and $48 \%$ said that they would vote for his Democratic Party opponent, Senator John Kerry. The poll division thus favoured Bush with $50.5 \%$ of two-party support. ${ }^{5}$ Based on the historical relationship of the September poll to the November vote as measured by the regression of the poll on the vote, Bush should have been expected to receive in the vicinity of $51.8 \%$ of the two-party vote. His actual vote in November was only about 0.5 less than this expectation. Thus, both public opinion measures indicated that the public was slightly inclined - entering the 2004 campaign - to re-elect President Bush. His public opinion numbers were not nearly as high as many inparty candidates on either approval or preference, but appear to have been high enough.

\section{The Election-Year Economy}

A second fundamental is the election-year economy. The pre-election-year economy is important to the vote for many, but should already be reflected in the public opinion measures. The most recent economic developments, however, may not be fully incorporated into the public's views, but may affect these views over 


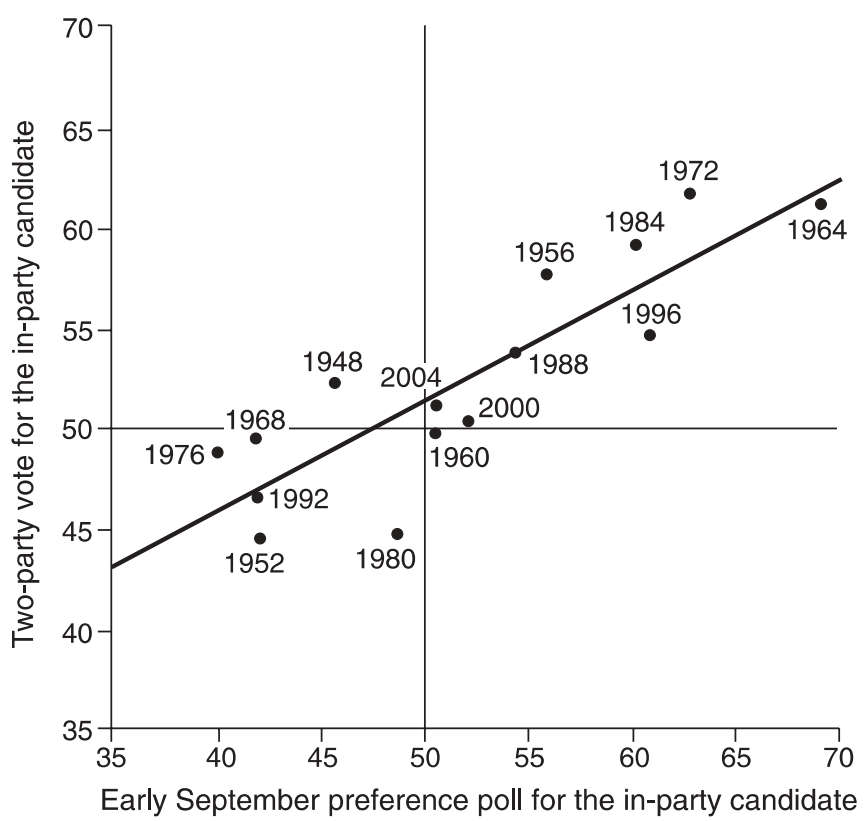

Figure 2. Preference poll support for the in-party's candidate in early September and the inparty's two-party presidential vote, 1948-2004.

Note: The vote for the in-party and the early September trial-heat poll are divisions of major two-party preferences. The estimated regression is: in-party vote $=24.00+(0.55 \mathrm{x}$ trial-heat poll for the incumbent party candidate). The adjusted R-square is 0.73 . The t-ratio for the approval coefficient is 6.19 . The standard error of the equation is 2.92 . The trial-heat poll is of registered voters. The data are from Gallup (2004) and Moore et al. (2001).

the course of the campaign. It is important to keep in mind that voters do not need to know anything about economic reports to respond to the economic developments. As a group, they should experience the ups and downs of the economy in their daily lives. Additionally, the impact of the economy is quite likely not strictly an economic matter. That is, prosperity creates good will for the in-party on all issues. If the economy causes people to feel good, this carries over to feelings about the in-party's candidate. On the other hand, tough economic times may make for an electorate less receptive to the in-party. Instead of looking for a reason to return the in-party to office, they may be looking for a reason to turn them out of office.

Table 1 presents election years from 1948-2004 sorted by gross domestic product (GDP) growth during the first half of the election year (January to June) and by the second quarter of the election year (April to June) along with the associated in-party votes for these years. The breaks in each listing separate election-year economies into those that were very good (more than $4 \%$ growth), middling ( 2.5 to $4 \%$ growth), and not so good (less than $2.5 \%$ growth). It is clear that most election-year economies are 
Table 1. Election-year economies and the in-party candidates' share of the two-party popular vote, $1948-2004$

\begin{tabular}{|c|c|c|c|c|c|}
\hline \multicolumn{3}{|c|}{ First Half Year GDP Growth } & \multicolumn{3}{|c|}{ Second Quarter GDP Growth } \\
\hline Year & GDP growth $\%$ & $\begin{array}{l}\text { In-party vote } \\
\text { (Two-party \%) }\end{array}$ & Year & GDP growth \% & $\begin{array}{l}\text { In-party vote } \\
\text { (Two-party \%) }\end{array}$ \\
\hline 1972 & 8.4 & 61.8 & 1972 & 9.4 & 61.8 \\
\hline 1968 & 7.6 & 49.8 & 1948 & 7.1 & 52.3 \\
\hline 1984 & 7.4 & 59.2 & 1984 & 6.9 & 59.2 \\
\hline 1964 & 6.9 & 61.3 & 1968 & 6.8 & 49.6 \\
\hline 1948 & 6.8 & 52.3 & 2000 & 6.3 & 50.3 \\
\hline \multirow[t]{2}{*}{1976} & 6.0 & 49.0 & 1988 & 5.1 & 53.9 \\
\hline & & & 1964 & 4.7 & 61.3 \\
\hline 1992 & 4.0 & 46.5 & & & \\
\hline 2004 & 3.9 & 51.2 & 1992 & 3.9 & 46.5 \\
\hline 2000 & 3.7 & 50.3 & 2004 & 3.3 & 51.2 \\
\hline 1988 & 3.5 & 53.9 & 1956 & 3.2 & 57.8 \\
\hline 1960 & 3.4 & 49.9 & 1976 & 3.0 & 49.0 \\
\hline 1996 & 2.9 & 54.7 & 1996 & 2.8 & 54.7 \\
\hline 1952 & 2.2 & 44.6 & 1952 & 0.3 & 44.6 \\
\hline 1956 & 0.6 & 57.8 & 1960 & -2.0 & 49.9 \\
\hline \multirow[t]{2}{*}{1980} & -3.4 & 44.7 & 1980 & -8.1 & 44.7 \\
\hline & In-party won & In-party lost & & In-party won & In-party lost \\
\hline $4 \%+$ & 4 & 2 & & 6 & 1 \\
\hline $2.5 \%$ to $4 \%$ & 4 & 2 & & 3 & 2 \\
\hline $2.5 \%-$ & 1 & 2 & & 0 & 3 \\
\hline Correlation & \multicolumn{2}{|c|}{0.51} & & \multicolumn{2}{|c|}{0.60} \\
\hline
\end{tabular}

Source: Bureau of Economic Analysis (2004) and Moore et al. (2001).

in good shape and that the state of the election-year economy is related to the vote ( $\mathrm{r}=.51$ for the first half and .60 for the second quarter). The relationships are even stronger when the incumbent is seeking re-election $(r=.58$ and .68 respectively). Although these correlations fall short of supporting visions of an economically driven electorate, they do indicate that the election-year economy matters.

The importance of the economy is evident in the breakdown into the three groups. It is unusual for in-party candidates to lose in election-year economies growing at rates in excess of $4 \%$. The only candidates who lost when there were strong electionyear economies were Hubert Humphrey in 1968 with a party divided on both its left and right and racked by divisions over the Vietnam War and Gerald Ford in 1976 who carried the weight of Watergate and the Nixon pardon into the campaign. Both 
lost in very close elections. At the other end of the spectrum, it is unusual to win with a weak election-year economy. The shrinking economy of 1980 undoubtedly contributed to Jimmy Carter's loss that year. The only surviving candidate from a weak election-year economy was Dwight Eisenhower in 1956. Eisenhower's second-quarter rebound helped to offset a very weak first quarter that year.

Between the strong and weak election-year economies are a set of years with growth between 2.5-4\%. The electoral record here, as one would expect, is mixed. In-party candidates running under these conditions could just as easily win or lose. This is where the 2004 election-year economy fits. The first half growth rate of $3.8 \%$, as indicated in the September 2004 release by the Bureau of Economic Analysis (BEA), is at the median of the previous 14 elections. The second quarter (again, as indicated by the BEA in September) was a bit weaker, but still in the middle grouping. The economic numbers in 2004 for Bush were actually a bit stronger than those in 1996 for Clinton, the most recent previous incumbent to win re-election. Economic growth in the first half of 2004 was a full point stronger than it was in 1996 and the second quarter in 2004 was about a half-point stronger than during the same period in 1996. Ironically, neither 1996 nor 2004 (in retrospect with the revised BEA numbers) were quite as strong as the economy under which the elder Bush was defeated by Clinton in 1992 - demonstrating (as the correlations indicated) that elections are not driven by the election-year economy alone. ${ }^{6}$ In this light, the economic fundamentals of the 2004 election might be best described as neutral or tilting slightly in favour of the incumbent - consistent with President Bush's relatively narrow majority over Senator Kerry.

\section{Incumbency and Party-Terms}

The third fundamental is incumbency. Incumbent presidents enjoy several advantages over non-incumbents. First, risk avoidance suggests that voters would prefer continuity to change - keeping a president in office over requiring a new officeholder to "learn the ropes". Second, the images of incumbents are enmeshed with the elevated images of the office. Efforts to blur the distinction between the person and the office is the essence of the "Rose Garden" strategy. Third, incumbents can use the powers of the presidency, including directing public debate to issues on which they have an electoral advantage.

Beyond the personal advantages of incumbents, political parties enjoy a "term" advantage if they are seeking a second consecutive term. If the in-party seeks simply a second term voters are inclined to see this as a reasonable length of service to implement a programme. Beyond this, the parties are again on a level playing-field. Disappointments accumulate, party unity strains and presidential agendas become played-out. The appeal of continuity by the in-party is offset by the appeal for change from the out-party.

Table 2 displays the three incumbency and party-term situations: no incumbent in the race, an incumbent seeking more than a second consecutive term for his party and an incumbent seeking a second consecutive term for his party. The table displays the 
Table 2. Presidential Incumbency, party-terms and the vote, 1948-2004

\begin{tabular}{|c|c|c|c|}
\hline \multirow[b]{2}{*}{ Vote $\%$} & \multirow[b]{2}{*}{$\begin{array}{l}\text { In-party non- } \\
\text { incumbents }\end{array}$} & \multicolumn{2}{|c|}{ Incumbents } \\
\hline & & $\begin{array}{l}\text { Beyond first } \\
\text { party-term }\end{array}$ & $\begin{array}{l}\text { First } \\
\text { party-term }\end{array}$ \\
\hline $62>$ & & & $\begin{array}{l}\text { Nixon } 72 \\
\text { Johnson } 64\end{array}$ \\
\hline \multicolumn{4}{|l|}{$60>$} \\
\hline $58>$ & & & $\begin{array}{l}\text { Reagan } 84 \\
\text { Eisenhower } 56\end{array}$ \\
\hline \multicolumn{4}{|l|}{$56>$} \\
\hline & & & Clinton 96 \\
\hline 54 & Bush 88 & & \\
\hline $52>$ & & Truman 48 & Bush 04 \\
\hline \multicolumn{4}{|c|}{ 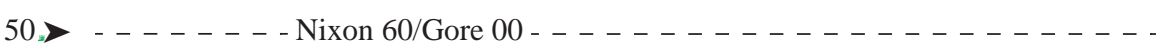 } \\
\hline & Humphrey 68 & Ford 76 & \\
\hline \multicolumn{4}{|l|}{$48>$} \\
\hline & & Bush 92 & \\
\hline \multicolumn{4}{|l|}{$46>$} \\
\hline & Stevenson 52 & & Carter 80 \\
\hline \multicolumn{4}{|l|}{44} \\
\hline Median vote & $49.9 \%$ & $49.0 \%$ & $57.8 \%$ \\
\hline
\end{tabular}

Note: The number by the in-party candidate's name indicates the year of the election. The vote percentage is the two-party vote division. The median vote percentages (and Ns in parentheses) for the three situations for elections from 1868 to 2004 are: $49.9 \%$ (13), 52.3\% (9) and $54.7 \%$ (13), respectively

incumbency status of in-party candidates and their vote percentages for the 15 elections from 1948-2004. As is clear from this limited evidence, non-incumbents and incumbents representing a party seeking more than a second consecutive term seem to have no better prospects than candidates from the out-party (not in the White House). The median votes in both situations are near 50\%. Incumbents from parties simply seeking a second term, however, tend to do well. Six of the seven incumbents in this situation since 1948 (including President Bush in 2004) have been re-elected, usually by a wide margin. Jimmy Carter was the only president seeking a second party-term to be defeated since 1948 .

The pattern of substantially stronger showings by incumbents seeking a second party-term is confirmed in examining the much longer stretch of electoral history from 1868-2004. There were 13 non-incumbent candidates of the in-party and their 
median vote was $49.9 \%$. There were nine incumbents seeking more than a second consecutive party-term and their median vote was 52.3\%. However, for the 13 incumbents seeking a second party-term the median vote was $54.7 \%$. Clearly, these incumbents had not yet worn out their welcome for a majority of voters. President Bush fits in this category in 2004. Although his vote percentage was not as large as most previous incumbents seeking a second term for their party, incumbency was clearly to Bush's advantage.

\section{Discussion}

In the Downsian world of electoral politics (Downs, 1957), candidates in a twoparty system are supposed to converge on the position of the median voter and this should produce a nearly evenly divided vote. In the real world of presidential elections, the candidates do not converge and competition is far from perfect. The fundamentals offer an explanation for this discrepancy. Candidates are not free to position themselves and their records to appeal equally to the median voter. The precampaign fundamentals, from the candidates' incumbency and party-term status to the election-year economy and the public's pre-campaign views, establish an advantage for one candidate over the other before the campaign begins. What candidates do with these advantages and disadvantages are up to them and often there are circumstances during the campaign that may be beyond either candidate's control. However, though the candidates' use of these raw materials matters, these campaign decisions are unlikely to change the foreseeable result (Campbell, 2000). The fundamentals affect both the starting point for each candidate and the resources they have to run the race and, unless these fundamentals are in balance or the advantaged candidate somehow wastes the opportunity they afford, the campaign is largely a process of converting the fundamental-affected predispositions into cast votes.

In the 2004 presidential election, the fundamentals tilted to the re-election of President Bush. They were not overwhelming by any means, but there were no factors that clearly favoured Senator Kerry. Both presidential approval and the presidential preference polls tilted in Bush's direction, not by wide margins but by what appear to be clear enough margins to make it his election to win or lose. The war on terrorism and the war in Iraq - seen as one and the same by some but separated by others, while reinforcing the substantial partisan divisions in the American electorate - on balance favoured Bush (at least leading into the campaign season). Incumbency, especially the fact that Republicans were seeking a second consecutive term and had not been in office for a longer period, clearly was to Bush's advantage. Finally, the election-year economy, whether the first half or the second quarter are examined, was in the middle ground. This probably did not help Bush's re-election much, but did not provide ammunition for Senator Kerry either. In conclusion, the forecast models based largely on these fundamentals anticipated a Bush vote in the $52-54 \%$ range. ${ }^{7}$ The actual vote fell just slightly short of that, suggesting that some unanticipated aspects of the campaign (possibly, the debates) may have helped Senator Kerry, but the election results ran quite true to form. 


\section{Notes}

1. Among the earliest of modern forecasting studies of the presidential vote were: Fair (1978); Sigelman (1979); Brody and Sigelman (1983); Lewis-Beck and Rice (1984); and Rosenstone (1983).

2. The forecasting models using public opinion indicators include: Abramowitz (2004); Campbell (2004a); Holbrook (2004); Lewis-Beck and Tien (2004); Wlezien and Erikson (2004). Each of these models also include economic indicators of various sorts. Lockerbie (2004) and Fair (2004) also use economic indicators. All of the models implicitly take an in-party advantage into account by orienting the analysis in terms of the in-party vote. In addition, Abramowitz (2004); Holbrook (2004); Lewis-Beck and Tien (2004); Lockerbie (2004); and Fair (2004) also include explicit inparty term or incumbency variables. The two-election autoregressive specification in Norpoth's model (2004) also effectively addresses the incumbency/party-term advantages.

3. For an elaboration of how the fundamentals structure the effects of campaigns and allow for the prediction of presidential elections, see Campbell (2000).

4. This conclusion is based on the standardized coefficients in most forecasting equations. For example, in the Labor Day preference poll and economy equation (Campbell, 2004a), the standardized coefficients are .73 for the poll and .42 for the economy.

5. Among likely voters the division favoured Bush by $53.6 \%$. By mid-September, Bush was favored by $54.2 \%$ of registered and $55.5 \%$ of likely voters. There is considerable controversy over the "likely voter" screen used by Gallup and others. On the one hand, it can be more volatile because of the use of political interest in the screen (see Erikson et al. 2004. On the other hand, with liberalized voter registration laws like "motor voter", there should be a greater discrepancy between registered voters and actual voters than in past elections and a properly constructed likely voter screen could take this into account. While the intent of capturing likely voters is laudable, the increased volatility and inaccuracy created by the attempts thus far make the registered voter division the more reliable division.

6. The pre-election year economy in 1992, however, was substantially weaker than those leading into either 1996 or 2004. The annual GDP growth in the previous two years (first quarter of year two to first quarter of year four in the term) was .8\% in 1992 compared to $2.9 \%$ in 1996 and $3.5 \%$ in 2004. Whereas only $10 \%$ of Gallup respondents in August of the election year rated the economy as excellent or good in 1992, 37\% did so in 1996 and 39\% did so in 2004. By comparison, 74\% were this positive about the economy in August 2000.

7. As of 6 September 2004, with one exception, the political science forecast models predicted a Bush popular vote plurality. From low to high, the forecasts of the popular two-party vote for Bush were $49.9 \%$ by Lewis-Beck and Tien, 51.7 to $52.9 \%$ by Wlezien and Erikson, $53.7 \%$ by Abramowitz and $53.8 \%$ by Campbell. The author's convention bump model indicated a $52.8 \%$ Bush vote. Using registered rather than likely voters in the polls would have lowered the expected Bush vote to 51.6 to $52.3 \%$ for Bush. A higher set of forecasts were $56.1 \%$ by Holbrook, $54.7 \%$ by Norpoth, and $57.6 \%$ by Lockerbie. Neither of the latter include an indicator of the public opinion fundamental. Articles explaining these forecast models and their 2004 predictions were published in a symposium in the October 2004 issue of PS: Political Sciences \& Politics (Campbell, 2004b). Economist Ray Fair's forecast at that time was for a Bush vote of $57.5 \%$.

\section{References}

Abramowitz, A.I. (2004) When good forecasts go bad: the time-for-change model and the 2004 presidential election, PS: Political Science \& Politics, 37(4), pp. 745-746.

Brody, R. \& Sigelman, L. (1983) Presidential popularity and presidential elections: an update and extension, Public Opinion Quarterly, 47(3), pp. 325-328.

Bureau of Economic Analysis (2004) Website, available at http://www.bea.doc.gov/.

Campbell, J.E. (2000) The American Campaign: U.S. Presidential Elections and the National Vote (College Station, TX: Texas A\&M University Press). 
Campbell, J.E. (2004a) Forecasting the presidential vote in 2004: placing preference polls in context, PS: Political Science \& Politics, 37(4), pp. 763-767.

Campbell, J.E. (ed.) (2004b) The 2004 presidential election forecasts, PS: Political Science \& Politics, 37(4), pp. 733-767.

Downs, A. (1957) An Economic Theory of Democracy (New York, Harper).

Erikson, R., Panagopoulos, C. \& Wlezien, C. (2004) Likely (and unlikely) voters and the assessment of campaign dynamics, Public Opinion Quarterly, 68(4), pp. 588-601.

Fair, R.C. (1978) The effect of economic events on votes for president, Review of Economics and Statistics, 60(2), pp. 159-173.

Fair, R.C. (2004) Website, available at http://fairmodel.econ.yale.edu/vote2004/index2htm.

Gallup Organisation (2004) Website, available at http://www.gallup.com.

Holbrook, T.M. (2004) Here We Go Again: A Forecast of the 2004 Presidential Election, PS: Political Science \& Politics, 37(4), pp. 759-761.

Lewis-Beck, M.S. \& Rice, T.W. (1984) Forecasting presidential elections: a comparison of naive models, Political Behavior, 6(1), pp. 9-21.

Lewis-Beck, M.S. \& Tien, C. (2004) Jobs and the job of president: a forecast for 2004, PS: Political Science \& Politics, 37(4), pp. 753-758.

Lockerbie, B. (2004) A look to the future: forecasting the 2004 presidential election, PS: Political Science \& Politics, 37(4), pp. 741-743.

Moore, J.L. Preimesberger, J.P. \& Tarr, D.R. (2001) Congressional Quarterly's Guide to U.S. Elections (Washington, DC: CQ Press).

Norpoth, H. (2004) From primary to general election: a forecast of the presidential vote, PS: Political Science \& Politics, 37(4), pp. 737-740.

Rosenstone, S.J. (1983) Forecasting Presidential Elections (New Haven, CT: Yale University Press).

Sigelman, L. (1979) Presidential popularity and presidential elections, Public Opinion Quarterly, 43(4), pp. 532-534.

Wlezien, C. \& Erikson, R.S. (2004) The Fundamentals, the Polls, and the Presidential Vote, PS: Political Science \& Politics, 37(4), pp. 747-751. 